\title{
An R-L Static Var Compensator (SVC)
}

\author{
A. J. Onah, E. E. Ezema and I. D. Egwuatu
}

\begin{abstract}
Traditional static var compensators (SVCs) employ shunt reactors and capacitors. These standard reactive power shunt elements are controlled to produce rapid and variable reactive power. Power electronic devices like the thyristor etc. are used to switch them in or out of the network to which they are connected in response to system conditions. There are two basic types, namely the thyristor-controlled reactor (TCR), and the thyristor-switched capacitor (TSC). In this paper we wish to investigate a compensator where the reactor or capacitor is replaced by a series connected resistor and reactor $(R-L)$. The performance equations are derived and applied to produce the compensator characteristics for each of the configurations. Their performances are compared, and the contrasts between them displayed. All three configurations are made to achieve unity power factor in a system.
\end{abstract}

Index Terms - reactive power, static var compensator, resistor, inductor, power transmission.

\section{INTRODUCTION}

SVC is a shunt reactive compensation controller [1] comprising of a combination of fixed capacitor or thyristorswitched capacitor in conjunction with thyristor-controlled reactor. SVCs have thus been used for years by utilities to control reactive power flow in transmission and distribution systems and consequently, help to improve power factor, stabilize weak systems, minimize line $I^{2} R$ losses, increase power transfer capability, enhance transient and steady-state stability, balance three-phase loads, damp oscillations, reduce voltage flicker and provide greater dynamic voltage regulation [2]-[6]. Limiting the flow of load reactive current along the transmission lines reduces transmission losses which will, in turn, lead to substantial reduction in the cost of both power capacity and energy production [7]. In principle, all shunt controllers inject current into the system at the point of connection [8]. The aim of this paper is to investigate a shunt static var compensator (SVC) which consists of series $R-L$ elements in the place of the commonly used reactor or capacitor as reactive power elements. The performance of this compensator is analyzed and compared with the existing Thyristor-Controlled Reactor (TCR) and Thyristor-Switched Capacitor (TSC) compensators. The proposed compensator is connected in parallel with and near the load. It provides dynamic var compensation and uses combinations of resistive and inductive elements with solid-state devices, for switching to achieve the goals stated above. The contrasts between this compensator configuration and the TCR and TSC are obtained and displayed. The three topologies are shown in Fig. 1.

Published on December 14, 2020

A. J. Onah, Michael Okpara University of Agriclture, Umudike, Nigeria.

E. E. Ezema, Enugu State Polytechnic, Iwollo, Nigeria.

I. D. Egwuatu, Wiez Engineering, Nigeria.
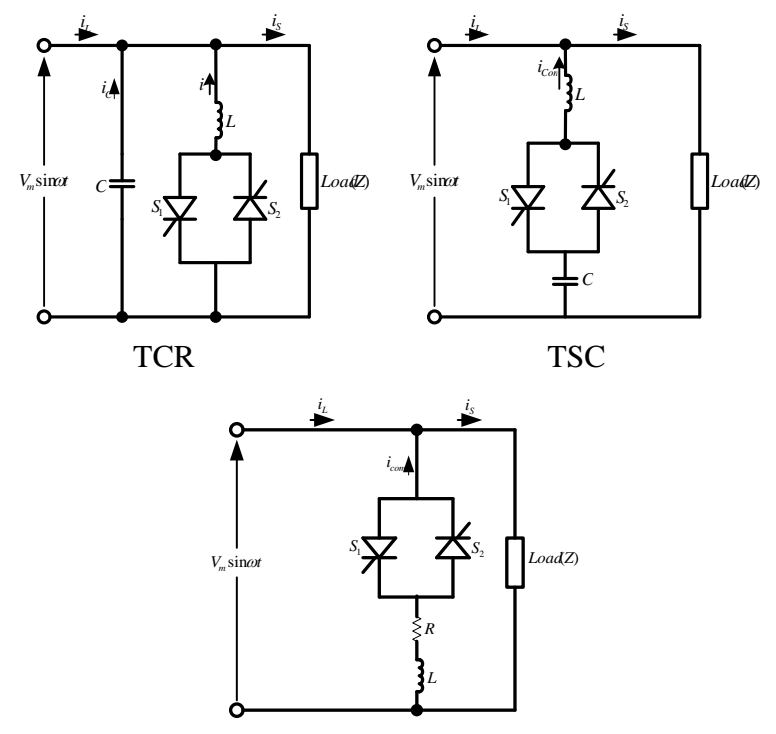

TSRL

Fig. 1. TCR, TSC and TSRL topologies.

\section{THE TCR CONFIGURATION}

Fig. 2 is the TCR configuration.

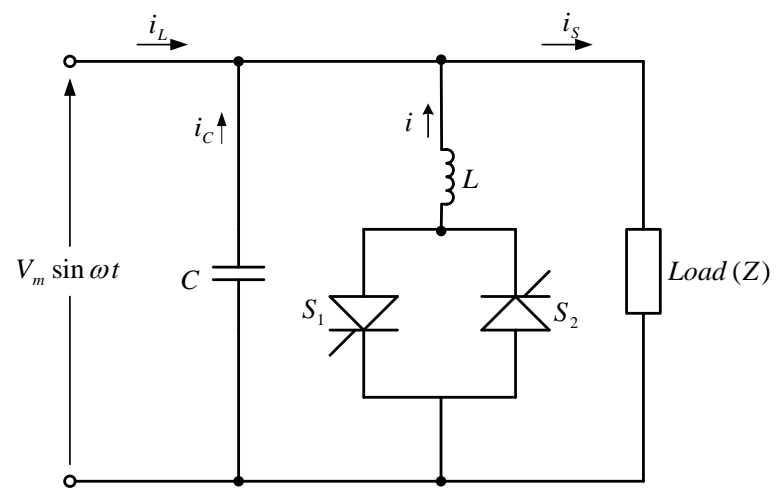

Fig. 2. Thyristor-Controlled Reactor (TCR).

In this SVC, a bank of static switches connected in antiparallel is connected in series with an inductor [9]-[11]. This arrangement is placed in parallel with one or more constantly energized capacitor banks. This is also known as fixed capacitor, thyristor-controlled reactor (FC-TCR) static var compensator (SVC). A constant quantity of vars are supplied by the capacitor to the system, while the reactor supplies variable lagging current in accordance with the firing angle of the high-power switches. The inductive current counters the capacitive current. The firing angle is varied between 90 and $180^{\circ}$, thereby adjusting continuously the magnitude of current and apparent inductance of the reactor. Phase-angle $(\alpha)$ control gives rise to harmonic currents generation, and so filters are needed in order to produce harmonic-free current. 
It can be shown that the network in Fig. 2 is operating at 0.7 power factor, where $v_{S}=V_{m} \sin \omega t$ and the load, $Z=6+j 6.1$. Fig. 3 shows the source voltage $\left(v_{S}\right)$, load current $\left(i_{L}\right)$ and load reactive power $\left(q_{L}\right)$.The rms values of $v_{S}$ and $i_{L}$ is $220 \mathrm{~V}$ and $25.7 \mathrm{~A}$ respectively. The $I^{2} R$ loss of this system is equal to $793 \mathrm{~W}$, where the line resistance $R=1.2 \Omega$.

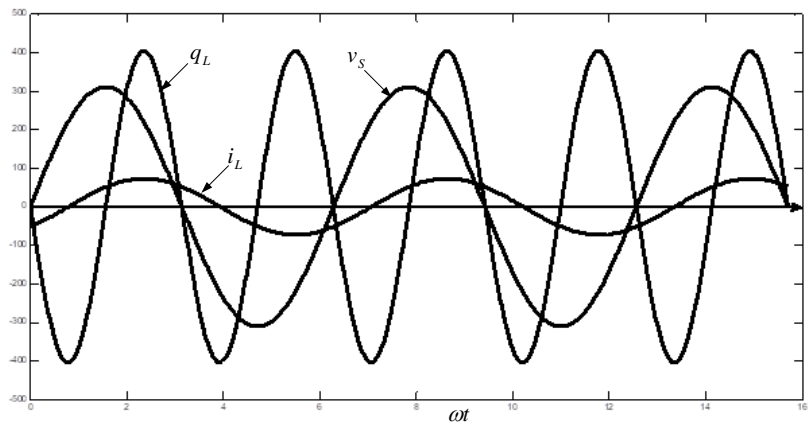

Fig. 3 Source voltage, load current, and load reactive power.

The inductor current in Fig. 2 can be found as follows:

For the positive half-cycle of the system voltage:

$L \frac{d i}{d t}=V_{m} \sin \omega t$

The solution of equation (1) is a general solution given as:

$$
i=-\frac{V}{\omega L} \cos \omega t+A
$$

where $A$ is the constant of integration.

At $\omega t=\alpha, i=0$, and $A=\frac{V_{m}}{\omega L} \cos \alpha$.

So,

$i=\frac{V}{\omega L}(\cos \alpha-\cos \omega t)$

Similarly, it can be shown that, for the negative halfcycle, when $\omega t=\pi+\alpha$.

$i=\frac{V}{\omega L}(\cos \alpha+\cos \omega t)$

By Fourier analysis, the inductor (reactor) current is:

$i=\frac{1}{2} a_{o}+\sum_{n=1}^{\infty}\left(a_{n} \cos n \omega t+b_{n} \sin n \omega t\right)$

$a_{o}=\frac{V}{2 \pi \omega L}\left\{\int_{\alpha}^{2 \pi-\alpha}(\cos \alpha-\cos \omega t) d \omega t-\int_{\pi+\alpha}^{3 \pi-\alpha}(\cos \alpha+\cos \omega t) d \omega t\right\}$

$a_{n}=\frac{V}{2 \pi \omega L}\left\{\int_{\alpha}^{2 \pi-\alpha}(\cos \alpha-\cos \omega t) \cos n \omega t d \omega t-\int_{\pi+\alpha}^{3 \pi-\alpha}(\cos \alpha+\cos \omega t) \cos n \omega t d \omega t\right\}$
$b_{n}=\frac{V}{2 \pi \omega L}\left\{\int_{\alpha}^{2 \pi-\alpha}(\cos \alpha-\cos \omega t) \sin n \omega t d \omega t-\int_{\pi+\alpha}^{3 \pi-\alpha}(\cos \alpha+\cos \omega t) \sin n \omega t d \omega t\right\}$

(8)

The inductor current is shown in Fig. 4.

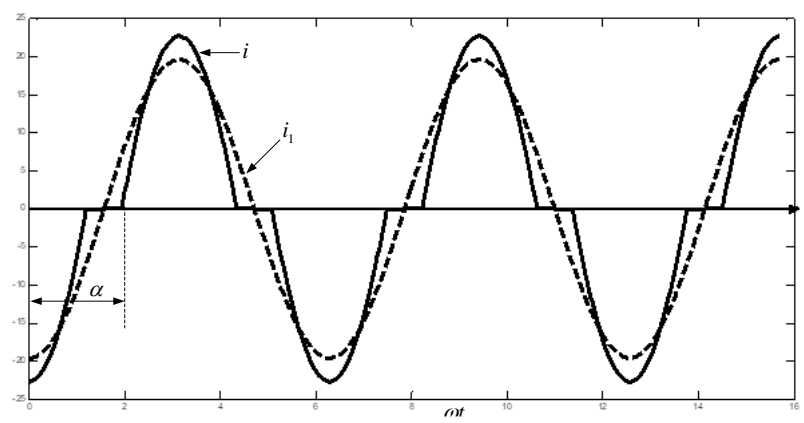

Fig. 4. Inductor current.

$i$ Inductor current; $i_{1}$ fundamental component.

The total harmonic distortion (THD) of $i$ is $24.3 \%$.

The capacitor current is:

$I_{C}=\omega C V_{m}$

Thus, the compensator output current is:

$i_{\text {com }}=i+I_{C}$

$\frac{\pi}{2} \leq \alpha \leq \pi$

The currents waveforms of the compensator are shown in Fig. 5.

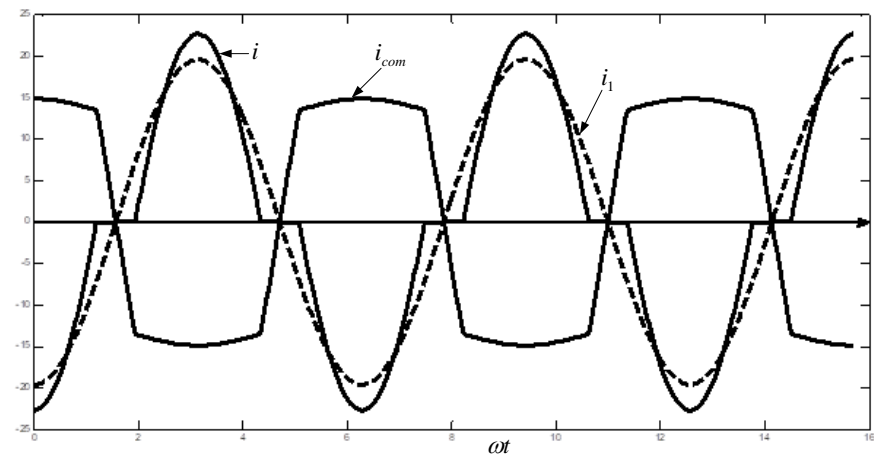

Fig. 5. Currents' waveforms of compensator.

The compensator output current combines with the load current to produce the resultant line current $\left(i_{S}\right)$ from the source, i.e.

$i_{S}=i_{L}+i_{c o m}$

These currents are shown in Fig. 6. 


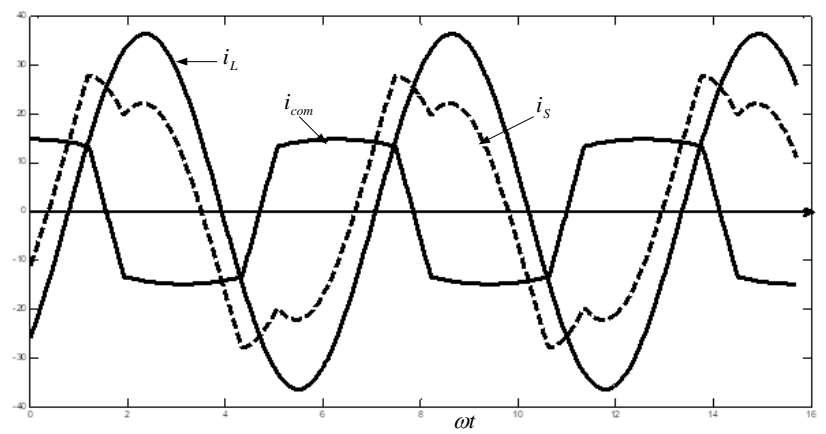

Fig. 6. Load current, compensator current and line current.

The line current, together with the system voltage is shown in Fig. 7.

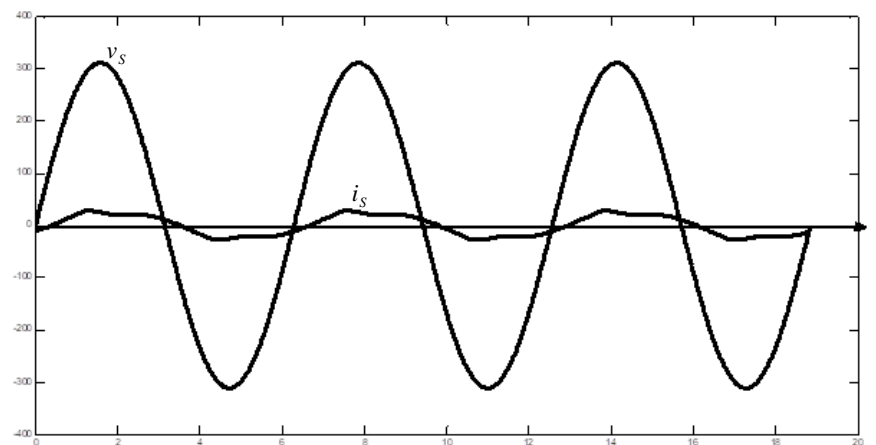

Fig.7 System voltage and line current after compensation.

The system operating power factor has been raised to 1.0 by the application of the TCR, where $\alpha=110^{\circ}$. The $I^{2} R$ loss of the transmission line is $468 \mathrm{~W}$ - reduction of power loss by $41 \%$. A filter will be required to suppress the harmonics. Fig. 8 shows the reactive powers due to the load and the compensator.

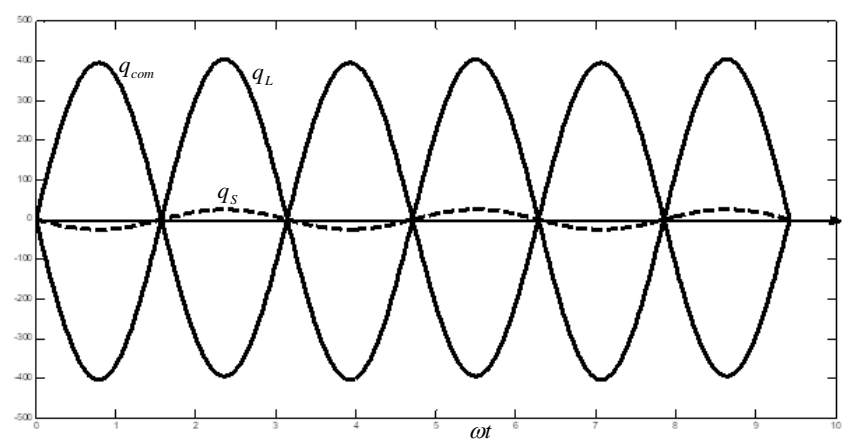

Fig. 8 Waveforms of reactive powers.

$q_{L}-$ Reactive power drawn by load.

$q_{\text {com }}$ - Reactive power supplied by compensator.

$q_{S}$ - Resultant reactive power flowing on the transmission line after compensation. It is given as:

$q_{S}=q_{L}+q_{\text {com }}$

\section{THE TSC CONFIGURATION}

Fig. 9 shows the TSC configuration.

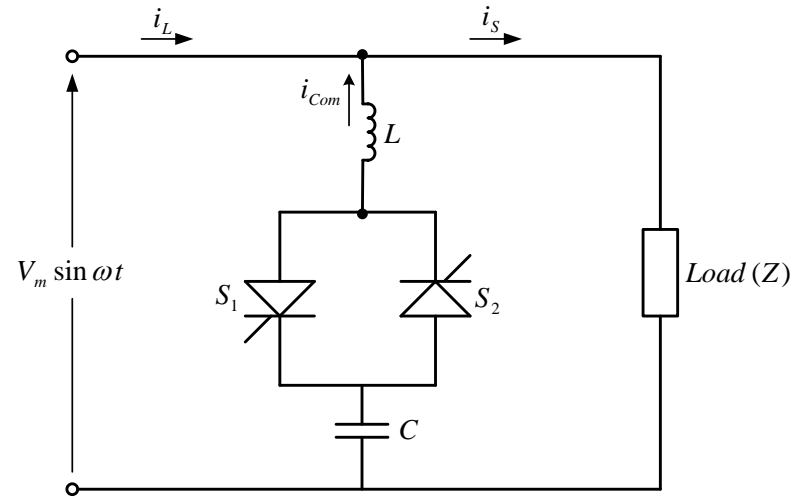

Fig. 9. Thyristor-switched capacitor (TSC).

TSC is a shunt-connected thyristor-switched capacitor whose effective reactance is varied in a stepwise manner by full- or zero-conduction operation of the switch [12][13].The TSC configuration - Fig. 9 [14]-[15] consists of a shunt capacitor bank which is switched on and off by a pair of anti-parallel switches. A small series damping inductor is used to limit the rate of rise of current through the switches and to prevent resonance with the system network. The capacitor current reaches a natural zero current when the voltage across the capacitor equals the maximum ac system voltage $V_{\mathrm{m}}$. At this point, the gate pulses of the switches are suppressed, and reactive power through the capacitor ceases abruptly. Harmonic currents generation by this SVC is quite low because of the zero-current switching [16]. When the switches are not conducting, the dc voltage on the capacitor and the ac system voltage add up to create voltage stresses of twice the system voltage across the switches. One of the main properties of this configuration is stepwise control. So, it has the disadvantage of non-continuous $\mathrm{VAr}$ compensation. The final information is the number of capacitor banks to be connected to the ac system. The control must be rigidly synchronized to the ac system voltage, to avoid misfiring. Thus, it has complex control system. Each capacitor bank requires a separate set of switches, making its construction less economical.

From Fig. 9:

$L \frac{d i_{c o m}}{d t}+v_{c}=V_{m} \sin \omega t$

where, $i_{\text {com }}$ is the current through the compensator and $v_{\mathrm{c}}$ is the voltage across the capacitor.

$i_{\text {com }}=C \frac{d v_{c}}{d t}$

$L C \frac{d^{2} v_{c}}{d t^{2}}+v_{c}=V_{m} \sin \omega t$

$$
\frac{d^{2} v_{c}}{d t^{2}}+\frac{1}{L C} v_{c}=\frac{V_{m}}{L C} \sin \omega t
$$


The solution of equation (16) can be found to be:

$v_{c}=A \cos \omega_{r} t+B \sin \omega_{r} t+\frac{V_{m}}{1-\omega^{2} L C} \sin \omega t$

From equation (14):

$i_{\text {com }}=-\omega_{r} C A \sin \omega_{r} t+\omega_{r} C B \cos \omega_{r} t+\frac{\omega C V_{m}}{1-\omega^{2} L C} \cos \omega t$

where,

$\omega_{r}=\sqrt{\frac{1}{L C}}$

is the system resonant frequency, and $A, B$ are arbitrary constants.

At switch-on, $t=0, \omega t=\alpha$ (thyristor firing angle),

$v_{C}=V_{C O}, i_{c o m}=0$,

$A=V_{c o}-\frac{V_{m}}{1-\omega^{2} L C} \sin \alpha$

and

$$
B=-\frac{\omega V_{m}}{\omega_{r}\left(1-\omega^{2} L C\right)} \cos \alpha
$$

Thus equation (18) becomes:

$i_{c o m}=\frac{\omega C V_{m}}{1-\omega^{2} L C} \cos \omega t-\frac{\omega C V_{m}}{1-\omega^{2} L C} \cos \alpha \cos \omega_{r} t+\omega_{r} C\left(\frac{V_{m} \sin \alpha}{1-\omega^{2} L C}-V_{c o}\right) \sin \omega_{r} t$

$V_{m}$ is the maximum value of the system voltage. Equation (19) is the current that flows through the compensator at a given time, $t$. The capacitor is switched in and out at the instant of current zero crossing, which also corresponds to the maximum value of the source voltage, $V_{\mathrm{m}}$, and the capacitor voltage $V_{c o}$ is equal to $V_{m}$ [17]-[18]. Thus the TSC employs integral half-cycle control where the capacitor is either fully in or out of the circuit. In other words, the average switching delay angle is one half of a cycle [19][20].

$i_{\text {com }}$ can be expressed in Fourier series as:

$i_{\text {com }}=\frac{a_{0}}{2}+\sum_{n=1,2}^{\infty}\left(a_{n} \cos n \omega t+b_{n} \sin n \omega t\right)$

where,

$a_{0}=\frac{1}{\pi} \int_{\alpha}^{3 \pi / 2}\left(x_{1} \cos \omega t-x_{1} \cos \alpha \cos \omega_{r} t+x_{2} \sin \omega_{r} t-x_{3} \sin \omega_{r} t\right) d \omega t$

$a_{n}=\frac{1}{\pi} \int_{\alpha}^{3 \pi / 2}\left(x_{1} \cos \omega t \cos n \omega t-x_{1} \cos \alpha \cos \omega_{r} t \cos n \omega t+x_{2} \sin \omega_{r} t \cos n \omega t-x_{3} \sin \omega_{r} t \cos n \omega t\right) d \omega t$

$b_{n}=\frac{1}{\pi} \int_{\alpha}^{3 \pi / 2}\left(x_{1} \cos \omega t \sin n \omega t-x_{1} \cos \alpha \cos \omega_{r} t \sin n \omega t+x_{2} \sin \omega_{r} t \sin n \omega t-x_{3} \sin \omega_{r} t \sin n \omega t\right) d \omega t$ where,

$$
\begin{aligned}
& x_{1}=\frac{\omega C V_{m}}{1-\omega^{2} L C} \\
& x_{2}=\omega_{r} C\left(\frac{V_{m} \sin \alpha}{1-\omega^{2} L C}\right) \\
& x_{3}=\omega_{r} C V_{c o}
\end{aligned}
$$

To improve the power factor, a TSC is switched on at the peak of the system voltage (i.e., when $\alpha=90^{\circ}$ ). Fig. 10 shows the current supplied by the compensator.

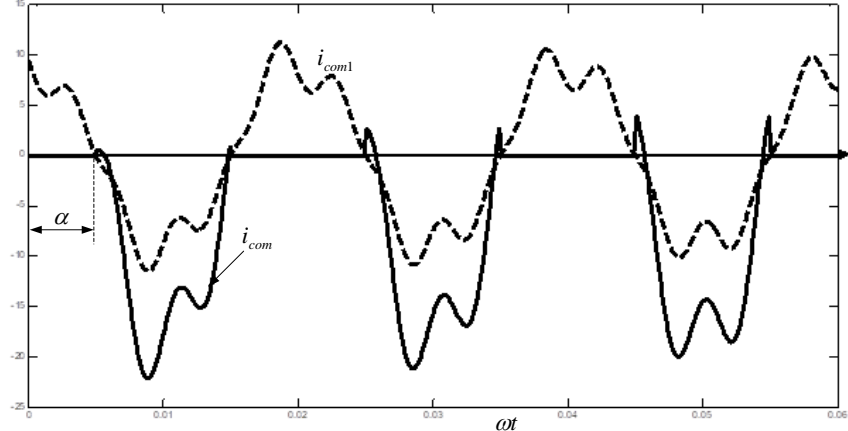

Fig. 10 Compensator current.

$i_{\text {com }}-$ Compensator current, $i_{\text {com } 1}-$ Fundamental component.

This plot is generated from equation (20). The resulting line current is given by:

$i_{S}=i_{L}+i_{C o m}$

These currents are shown in Fig. 11.

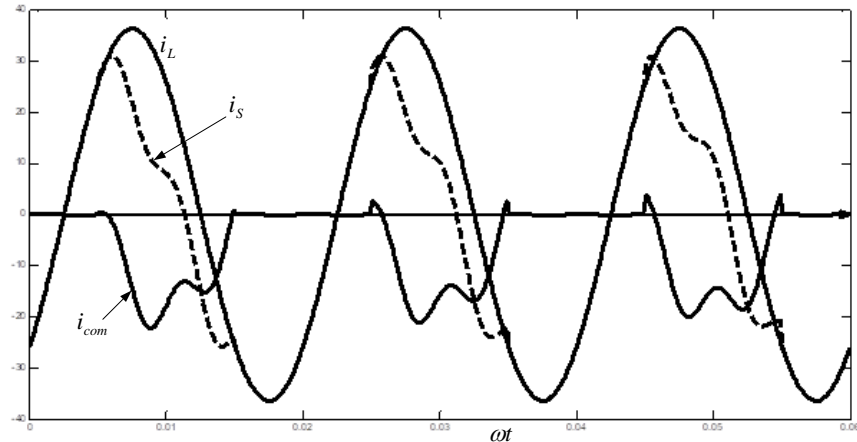

Fig. 11 Load current, compensator current, and line current.

Fig. 12 shows the system voltage and line current when the TSC is applied.

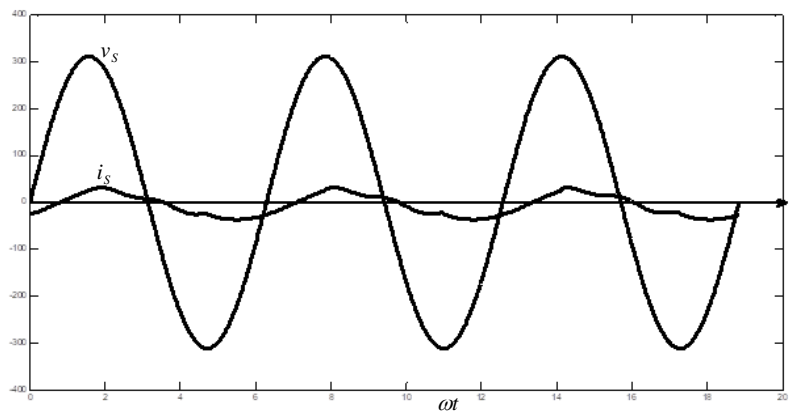

Fig. 12. System voltage and line current with the TSC applied. 
Here unity power factor is attained also. $I^{2} R=578 \mathrm{~W}$, $27 \%$ reduction in power loss. As stated earlier, harmonics generated here can be neglected. But the topology and control are more expensive. Fig. 13 is the waveforms of the associated reactive powers.

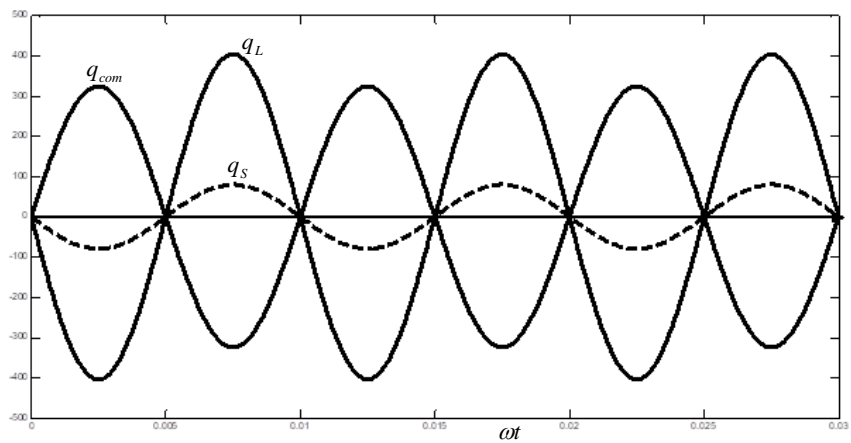

Fig. 13 Plots of reactive powers of the system.

\section{THE TSRL CONFIGURATION}

Fig. 14 shows the proposed $R L$-switched compensator.

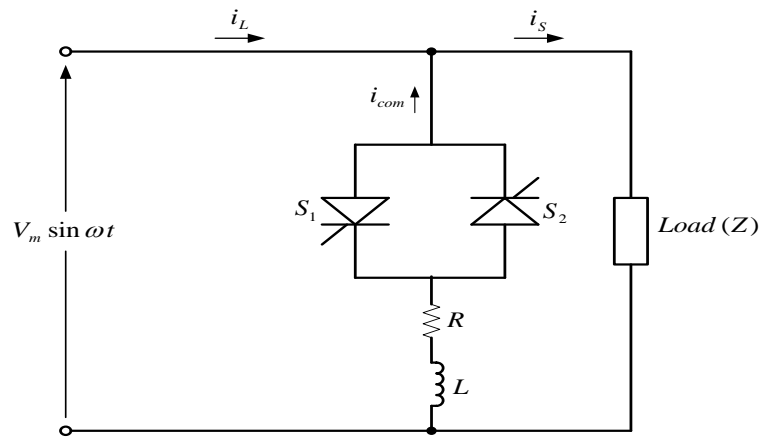

Fig. 14. Thyristor-switched RL Compensator.

The firing angle is varied between 90 and $180^{\circ}$ so as to continuously adjust the magnitude of the compensator current. Of course, phase-angle $(\alpha)$ control leads to harmonic currents generation, but depending on the firing angle, they can be negligible.

For the positive half-cycle of the supply voltage in Fig. 14, we have:

$$
L \frac{d i_{c o m}}{d t}+i_{c o m} R=V_{m} \sin \omega t
$$

The solution of equation (25) can be found to be:

$$
i_{c o m}=\frac{V_{m}}{Z} \sin (\omega t-\theta)+C e^{-\frac{R}{L} t}
$$

where, $\mathrm{C}$ is the constant of integration.

At switch-on, $\omega t=\alpha$ (thyristor firing angle), $i_{\text {com }}=0$,

$$
C=-\frac{V_{m}}{Z} \sin (\alpha-\theta) e^{\frac{R}{\omega L} \alpha}
$$

So,

$$
i_{\text {com }}=\frac{V_{m}}{Z}\left[\sin (\omega t-\theta)-\sin (\alpha-\theta) e^{\frac{\alpha-\omega t}{\tan \theta}}\right]
$$

For the negative half-cycle of the supply voltage, i.e., when $\omega t=(\pi+\alpha), i_{\text {com }}=0$ again, and

$$
i_{\text {com }}=-\frac{V_{m}}{Z}\left[\sin (\omega t-\theta)+\sin (\alpha-\theta) e^{\frac{\pi+\alpha-\omega t}{\tan \theta}}\right]
$$

$i_{\text {com }}$ can be expressed in Fourier series as:

$$
i_{\text {com }}=\frac{a_{0}}{2}+\sum_{n=1,2}^{\infty}\left(a_{n} \cos n \omega t+b_{n} \sin n \omega t\right)
$$

where,

$$
a_{0}=\frac{V_{m}}{\pi Z}\left\{\int_{\alpha}^{2 \pi-\alpha}\left(\sin (\omega t-\theta)-\sin (\alpha-\theta) e^{\frac{\alpha-\omega t}{\tan \theta}}\right) d \omega t+\int_{\pi+\alpha}^{3 \pi-\alpha}\left(\sin (\omega t-\theta)+\sin (\alpha-\theta) e^{\frac{\pi+\alpha-\omega t}{\tan \theta}}\right) d \omega t\right\}
$$

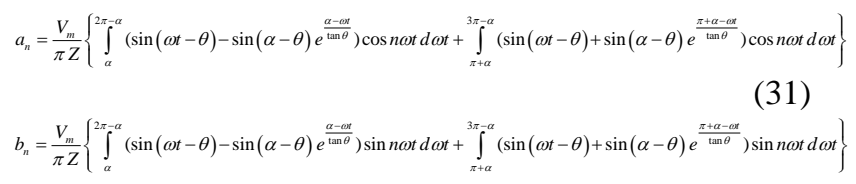

Equation (29) is plotted as in Fig. 15, showing the compensator output current.

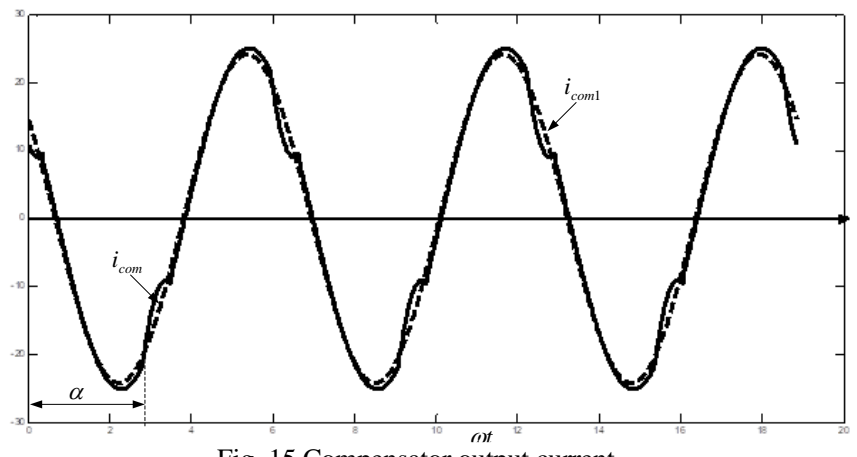

Fig. 15 Compensator output current

The THD of the compensator current is just $8.32 \%$, so filtering may not be required. The line current after compensation is:

$$
i_{S}=i_{L}+i_{c o m}
$$

These currents are shown in Fig. 16.

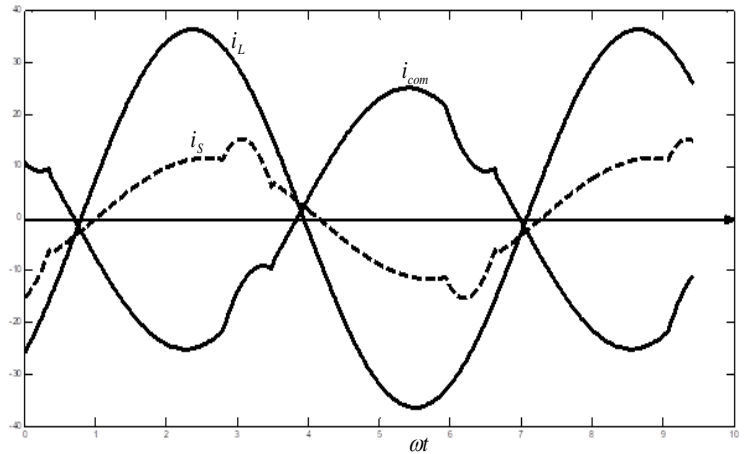

Fig. 16 Load current $\left(i_{L}\right)$, Compensator current $\left(i_{c o m}\right)$, and the resulting line current $\left(i_{S}\right)$ 
Fig. 17 shows the system voltage $\left(v_{s}\right)$ and the line current $\left(i_{s}\right)$.

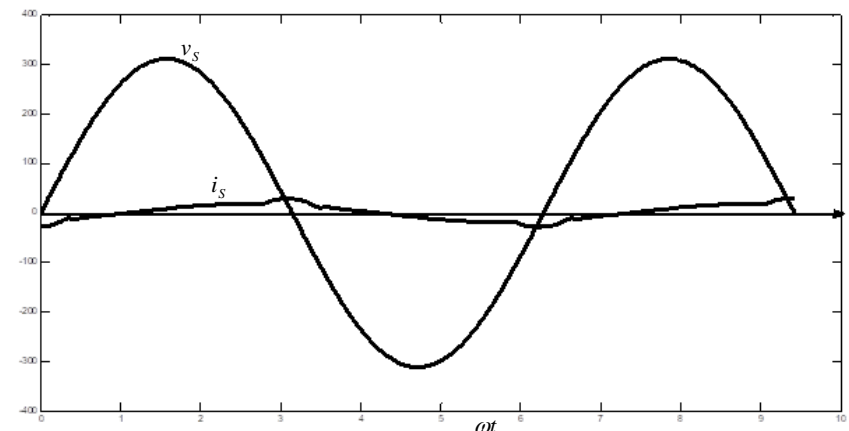

Fig. 17. System voltage and line current with the application of R-L compensator.

With this compensator, power factor of 0.99 is achieved. The $I^{2} R$ loss after compensation is equal to $141 \mathrm{~W}$, which is $82.2 \%$ reduction in power loss. The reactive powers due to the compensator and load are shown in Fig. 18.

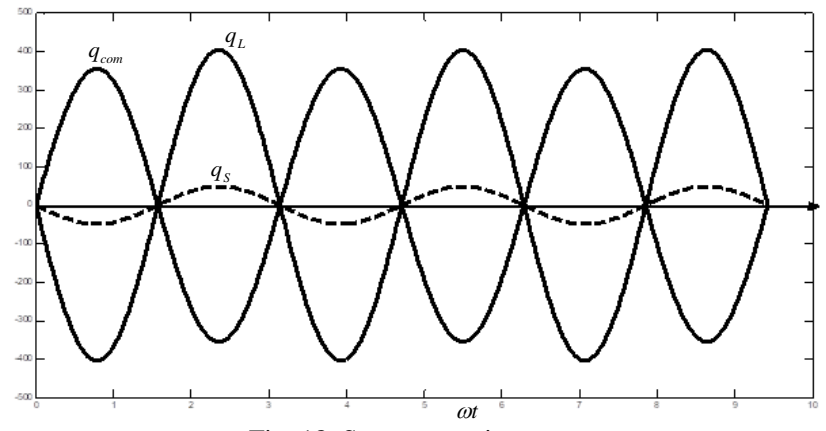

Fig. 18. System reactive powers.

Table 1 shows the results obtained for each of the SVC configurations.

TABLE 1: PERFORMANCE INDICES OF THE COMPENSATORS

\begin{tabular}{|c|c|c|c|c|c|}
\hline & $\begin{array}{l}\text { Power } \\
\text { factor }\end{array}$ & $\begin{array}{c}\text { Total } \\
\text { Harmonic } \\
\text { generation } \\
\text { (THD) } \%\end{array}$ & $\begin{array}{l}\text { Line current } \\
\text { (I) after } \\
\text { compensation } \\
\text { (A) }\end{array}$ & $\begin{array}{c}\text { Line } \\
\text { losses } \\
\left(I^{2} R\right) \\
(\mathrm{W})\end{array}$ & $\begin{array}{c}\text { Line } \\
\text { losses } \\
(\%)\end{array}$ \\
\hline TCR & 0.99 & $24.3 \%$ & 19.75 & 468 & 59 \\
\hline TSC & 0.99 & 0 & 21.95 & 578 & 73 \\
\hline TCRL & 0.99 & $8.32 \%$ & 10.83 & 141 & 17.8 \\
\hline
\end{tabular}

The losses in percentage are calculated with respect to 793W.

\section{CONCLUSION}

The equations governing the performances of the TCR, TSC, and TSRL compensators were derived and then used to illustrate how the reactive power drawn from the ac supply, by an inductive load, can be controlled in order to improve transmission and distribution lines performance. Each of the SVCs was able to raise power factor of a system from 0.7 to unity. Their performances were compared. The TCR generated much more current harmonics than the TSRL, and so would require filters. The TSC produced harmonic-free current but lacks continuous control strategy. Its circuit components are much more in number and must withstand higher voltage stress than the TCR and the TSRL components. The TSRL produces near harmonic-free current, and so it does not need a filter, its construction is simpler and more economical than others. With the TSRL application, the line current and losses after compensation are the least. These results are obvious from Table 1 .

\section{REFERENCES}

[1] Gyugyi L., Proceedings of the IEEE 76(4), 483 (1988).

[2] Weedy, B.M., "Electric Power Systems", John Wiley \& Sons, 1987, pp. 139-141.

[3] Jen-Hung Chen, Wei-Jen Lee, Mo-Shing Chen, "Using a Static Var Compensator to Balance a Distribution System", IEEE Transactions on Industry Applications, Vol. 35, No. 2, pp. 298-301, March/April 1999.

[4] Mustapha Benghanem and Azeddine Draou, "A new Modelling and Control Analysis of an Advanced Static Var Compensator using a Three-level (NPC) Inverter Topology", Journal of Electrical Engineering, Vol. 57, No. 5, pp. 285-290, 2006

[5] Xuechun Yu, Mustafa Khamash, Vijay Vittal, "Robust design of a Damping Controller for Static Var Compenastors in Power Systems", IEEE Transactions on Power Systems, Vol. 16, No. 3, 456-462, August 2001.

[6] M. Parniani, M.R. Iravani, "Optimal robust control design of static Var compensators", IEE Proc. - Gen. Transm. Distrib. Vol. 145, No. 3, pp. 301-307, May 1998.

[7] IEEE Special Stability Controls Working Group, "Static Var Compensator Models for Power Flow and Dynamic Performance Simulation", IEEE Transactions on Power Systems, Vol. 9, No. 1, pp. 229-240, February 1994.

[8] Georgilakis P. S. and Vernados P. G., "Flexible AC Transmission System Controllers: An Evaluation," Materials Science Forum Vol. 670 (2011) pp 399-406, Trans Tech Publications, Switzerland.

[9] Zhi, J. E., Chan, K. W., Fang, D. Z. (2006). A Practical Dynamic Phasor Model of Static Var Compensator. In: Proceedings of $2^{\text {nd }}$ International Conference on Power Electronics Systems and Applications: China, pp. 23-27

[10] Rao V.S. and Sanker Ram B. V. "Coordinated Control of PSS with FACTs Controllers for Dynamic Performance Enrichment", International Journal of Engineering Sciences and Research Technology, 5(10) October 2016, pp. 74-83.

[11] N. G. Hingorani, L. Gyugyi, Understanding FACTS: Concepts and Technology of Flexible AC Transmission Systems, IEEE, New York, 2000.

[12] Grampurohit S., Gadhavi T., Boksha P. and Surani R., "Comparison of FACT Devices to Control Reactive Power in Long Distance High Voltage Transmission Line," International Journal of Engineering Research \& Technology, Vol. 2 Issue 12, December - 2013, pp. 3236-3244

[13] A.-A. Edris, R. Adapa, M. H. Baker, L. Bohmann, K. Clark, K Habashi, L. Gyugyi, J. Lemay, S. Mehraban, A. K. Myers, J. Reeve, F. Sener, D. R. Torgerson, R. R. Wood, IEEE Transactions on Power Delivery 12(4), 1848 (1997)

[14] Bill Lockley and Gerard Philpoitt, "Static VAR Compensators - A solution to the big motor/weak system problem", 2000 IEEE IAS Annual Meeting, pp. 43-49.

[15] H. Frank and S. Ivner, "Thyristor-controlled Shunt Compensation in Power Networks", ASEA Journal, vol. 54, pp. 121-127, 1981.

[16] H. Frank and B. Landstrom, "Power Factor correction with Thyristor-Controlled Capacitors", ASEA Journal, vol. 45, no. 6, pp. 180-184, 1971

[17] Juan Dixon, Luis Moran, Jose Rodriguez, Ricardo Domke, "Reactive Powe Compensation Technologies, State-of-the-Art Review (Invited Paper)", Electrical Engineering Department, Universidad de Concepcion, Concepcion - Chile

[18] Scott Zemerick, Powsiri Klinkhachorn, Ali Feliachi, "Design of a Microprocessor-Controlled Personal Static Var Compensator (PSVC)", 2002 IEEE, pp. 1468-1473.

[19] Scott A. Zemerick, P. Klinkhachorn, A. Feliachi, "Prototype Design of a Personal Static Var Compensator", Advanced Power Engineering Research Center, West Virginia University, Morgantown, WV 26506 USA, 2002, pp. 311-315.

[20] Symonds, A. Electrical Power Equipment and Measurements: with heavy current electrical applications. Second edition. McGraw-Hill Book Company, London, 1980. 